\title{
INFLUENCIAS INTERNAS Y EXTERNAS SOBRE LA COOPERACIÓN INTERNACIONAL EN BOLIVIA DURANTE EL GOBIERNO DEL MAS (2006-2019)
}

Carolina Martínez*

\section{Resumen}

Al llegar a la presidencia de Bolivia en 2006, el Movimiento al Socialismo (MAS) se propuso refundar el Estado bajo los postulados del Vivir Bien. Este cambio de narrativa se evidenció en todos los ámbitos, y como consecuencia, impactó en la política interna y externa del país. Asimismo, se percibieron durante ese período cambios en el sistema internacional que también repercutieron en el accionar del gobierno masista.

En el presente trabajo se describen los principales acontecimientos de la política exterior del país andino como así también los hitos más relevantes del Sistema de Cooperación Internacional, para poder analizar el cambio de rol otorgado a la cooperación internacional en Bolivia durante los gobiernos del binomio Morales-Linera.

Palabras clave: Bolivia - política exterior - cooperación internacional - Ayuda Oficial al Desarrollo - Cooperación Sur-Sur.

INTERNAL AND EXTERNAL INFLUENCES ON INTERNATIONAL COOPERATION IN BOLIVIA DURING THE MAS GOVERNMENT (2006-2019)

\section{Abstract}

On reaching Bolivia administration in 2006, the Movimiento al Socialismo (MAS) proposed to reestablish the State under the philosophy of Vivir Bien. This change of narrative was evident in all areas, and as a consequence, it impacted the internal and external politics of the country. Likewise, changes in the international system had an effect on the actions of the Bolivian government during that period.

In this article, the main events of the foreign policy and the International Cooperation System will be described in order to analyze the change of the role granted to international cooperation in Bolivia during the governments of Morales-Linera.

\footnotetext{
* Licenciada en Relaciones Internacionales, Universidad Nacional de Rosario (UNR). Docente en la Facultad de Ciencia Política y RRII, UNR. Correo: carolina.martinez@fcpolit.unr.edu.ar ORCID: https://orcid.org/0000$\underline{0001-8261-8952}$
}

Esta obra se encuentra bajo la Licencia Creative Commons Reconocimiento - Compartir Igual (by-sa) 
Keywords: Bolivia, foreign policy, international cooperation, Official Development Assistance, South-South Cooperation.

TRABAJO RECIBIDO: 15/05/2021 - TRABAJO ACEPTADO: 18/06/2021 


\section{Introducción}

A principios de siglo, Bolivia, al igual que varios de sus vecinos sudamericanos, experimentó las consecuencias de las políticas neoliberales implementadas en la década anterior. Los años noventa estuvieron caracterizados por la crisis de los partidos tradicionales, el deterioro de la economía, la desigualdad y los altos índices de pobreza, entre otras características (Mayorga, 2006). Esta situación fue un factor determinante para darle impulso a la emergencia de movimientos sociales y políticos que demandaban transformaciones profundas. Así, América Latina comenzó a transitar un cambio político e ideológico que, en términos académicos, fue identificado como el "giro a la izquierda", "gobiernos progresistas", "gobiernos populistas", entre otras calificaciones ${ }^{1}$.

En el caso particular de Bolivia, las consecuencias negativas del período neoliberal, los cuestionamientos a los partidos de la "Democracia Pactada" y la necesidad de quiebre con el pasado, intensificaron el dinamismo que adquirieron los movimientos sociales y políticos en los primeros años del presente siglo. La victoria de Evo Morales Ayma con el Movimiento al Socialismo ${ }^{3}$ (MAS) en las elecciones presidenciales del 18 de diciembre de 2005, representó una muestra elocuente de este proceso. Un líder indígena y sindical asumió la presidencia con el $53.7 \%$ de los votos, generando un punto de inflexión en la historia socio-política boliviana. Es menester señalar que, a escasos meses de su llegada, el primer mandatario dispuso un conjunto de directrices orientadas a establecer la reestructuración del Estado y la sociedad.

El nuevo gobierno elaboró el Plan Nacional de Desarrollo "Bolivia Digna, Soberana, Productiva y Democrática para Vivir Bien. Lineamientos Estratégicos 2006 - 2011 ” (PND) ${ }^{4}$ tendiente a impulsar la construcción de un Estado Plurinacional en base al Vivir Bien.

Las propuestas de dicho Plan fueron la base del proceso de transformación emprendido y sus objetivos se enfocaron en la supresión de las causas que originaban la desigualdad y la exclusión social del país; en la participación social y comunitaria de toda la ciudadanía; en la diversificación de la matriz productiva; y en la construcción de un Estado con autodeterminación y con identidad propia en materia de política exterior (Ministerio de Planificación y Desarrollo, 2007).

\footnotetext{
${ }^{1}$ Entre algunos estudiosos de este fenómeno, se encuentran Carlos Vilas (2005); Carlos De La Torre (2013); Ludolfo Paramio (2006); Manuel Antonio Garretón (2006); Francisco Panizza (2009); Benjamín Arditi (2009); Diana Tussie y Pablo Heidrich (2008) y Carlos Moreira, Diego Raus y Juan Carlos Gómez Leyton (2008).

2 La "Democracia Pactada" fue un sistema de alianzas inter partidarias en el Congreso entre las principales fuerzas políticas del país -MNR; Acción Democrática Nacionalista (ADN) y el Movimiento de la Izquierda Revolucionaria (MIR)- para alternar su estadía en el Poder Ejecutivo. El Parlamento tenía un rol preponderante ya que era el encargado de intervenir en la elección del presidente cuando ninguno de los candidatos había obtenido la mayoría de los votos en las elecciones generales.

${ }^{3}$ Éste fue creado bajo el sostén de los sindicatos cocaleros con el fin de convertirse en un instrumento político de los movimientos campesinos e indígenas. En las elecciones de 2002 no obtuvo la presidencia, pero sí consiguió convertirse en la segunda fuerza electoral y el principal partido de oposición.

${ }^{4}$ Los ejes rectores de las políticas implementadas por el MAS se plasmaron en este PND y en las sucesivas renovaciones del mismo que sirvieron de guía al accionar del gobierno. A pesar de las modificaciones o actualizaciones, los planes siguieron conservando la lógica u orientación inicial. En este sentido, se encuentra el Plan de Desarrollo Económico y Social 2016-2020 (PDES) y la Agenda Patriótica 2025.
} 
Lo mencionado anteriormente posibilita inferir que la idea de cambio ha tenido un lugar protagónico en el ascenso del MAS al poder atravesando transversalmente su proyecto político. En tal sentido, si se observa la plataforma de campaña del MAS, se vislumbra que la narrativa refundacional estaba presente desde ese momento. Morales no había formado parte de los partidos de la "Democracia Pactada", no poseía origen empresario - como sí los referentes del MIR, la ADN o el MNR - y criticaba con vehemencia al modelo neoliberal.

La campaña del MAS-IPSP sería efectivamente articulada en torno al concepto de soberanía nacional, utilizado para denunciar tanto la injerencia de la embajada estadounidense en el debate público boliviano, como el sometimiento a EE.UU. de una clase política acusada, por su adhesión al neoliberalismo y a la erradicación de los cultivos de hoja de coca, de ser «vendepatria»y «entreguista» (Do Alto, 2008, p.30).

La posibilidad de consolidación de un quiebre con el pasado y, por ende, la construcción de un nuevo orden socio-político y económico es parte de un largo camino donde participaron diversos actores y factores involucrando tanto la política interna como externa del país.

En este sentido, el objetivo del presente trabajo es indagar acerca de la influencia de los factores domésticos y externos en el cambio de rol otorgado a la cooperación internacional en Bolivia durante los gobiernos del MAS. Para ello, se describirán los principales hitos de la política exterior boliviana en relación a la cooperación internacional (CI) a partir del nuevo marco normativo - Planes de Desarrollo y Constitución - y de las acciones implementadas, como así también se relatarán los cambios acontecidos en el Sistema de CI. Se tendrá en consideración los tres gobiernos ${ }^{5}$ del binomio Evo Morales Álvaro García Linera desde la llegada al Palacio Quemado en 2006 hasta las elecciones de octubre de $2019^{6}$.

\section{La Política Exterior boliviana a partir del nuevo marco normativo e institucional}

A los fines de este trabajo y siguiendo la definición brindada por Carla Morasso, se concibe a la política exterior como una política pública influenciada por los factores domésticos y externos "que expresa los objetivos de un Estado y los intereses de sus múltiples actores públicos y privados en su vinculación con el sistema internacional" (Morasso, 2015, p. 19).

A lo largo de la historia de Bolivia, la política exterior (PE) ha estado marcada por un alto grado de dependencia y subordinación a los principios sostenidos por los países desarrollados, en particular, Estados Unidos y los organismos financieros internacionales.

\footnotetext{
${ }^{5}$ Los períodos abarcados por cada gobierno fueron: 2006-2010; 2010-2014; 2014-2019. Vale aclarar que este último gobierno no fue completado por la renuncia forzada de Evo Morales luego de las elecciones de 2019. Con él renunciaron el Vicepresidente, la Presidenta del Senado y el Presidente de Diputados.

${ }^{6}$ El proceso político que se abre luego de los comicios de octubre 2019, además de estar cercano en el tiempo, cuenta con características muy particulares y complejas que exceden los propósitos de este trabajo.
} 
Esto se observó especialmente a partir de la segunda mitad de la década de los ochenta cuando los gobiernos comenzaron a implementar medidas de corte neoliberal. Siguiendo a Canelas y Verdes (2011),

durante la década de los noventa el criterio para evaluar si Bolivia tenía una buena política exterior venía otorgado exclusivamente desde fuera del país, y era asumido como válido internamente con poca resistencia, el ser buenos alumnos, "los aventajados", a la hora de cumplir el recetario del consenso de Washington era la asignatura más importante - numerosas menciones y premios fueron otorgados por esta tarea bien realizada -; también el cumplir a tiempo - y a veces con mayores exigencias de las pactadas - las certificaciones exigidas por EEUU en el marco de la lucha antidroga eran vitales para mantener estable la política exterior como también para que gran parte de los recursos de la cooperación no corriesen peligro de cesar fulminantemente (p. 240).

De esta manera, la PE se diseñaba según los intereses y/o contactos empresariales de las administraciones de turno. De acuerdo al PND "la política exterior boliviana de los últimos veinte años se caracterizó por ser errática e incoherente, basada en un modelo neoliberal que llevó al país a una profunda crisis económica y social" (Ministerio de Planificación y Desarrollo, 2007, p. 180). Los gobiernos de la "Democracia Pactada" obedecieron los postulados del Consenso de Washington con el propósito de conseguir los recursos financieros que permitieran sobrellevar la crisis económica de los años ochenta.

De este modo, en la etapa previa a la llegada del MAS, se identificaban tres rasgos claves de la PE del país andino: 1- la dependencia y la injerencia externa; 2- su impronta economicista de índole neoliberal y 3-el predominio de factores políticos e intereses de grupos de poder económico y el ejercicio de una PE neoliberal que no consideraba las demandas de la sociedad civil. Por lo anterior, sumado a las condiciones estructurales del país, se infiere que, en esta etapa, la PE boliviana tuvo un rol secundario y subordinado.

Por su parte, los principios y políticas sostenidas por el MAS han impactado en la configuración de la política externa nacional, la cual ha procurado un mayor nacionalismo económico, la diversificación de los socios políticos y comerciales y una inserción internacional más autónoma y soberana (Cunha Filho, 2016, p.143). La nueva orientación de la PE planteada por el MAS se centró en la valoración de la identidad nacional, la defensa de los recursos naturales y la articulación de alianzas estratégicas para mejorar la proyección geopolítica en la región y el mundo, teniendo como eje el Vivir Bien.

Para el MAS, los pilares establecidos en el PND en el eje de Bolivia Soberana, también fueron una herramienta que aportaron a la construcción de un Estado Plurinacional. De acuerdo al PND el gobierno de Morales propuso "constituir al nuevo Estado boliviano en un actor internacional independiente, soberano y con identidad propia, mediante una política exterior orientada a la acción política y diplomática con presencia de los pueblos y defensa de los recursos naturales" (Ministerio de Planificación y Desarrollo, 2007, p. 180).

A su vez, desde la lógica del MAS, los procesos de integración de los que participara Bolivia debían ser holísticos e integrales considerando como eje de su accionar a los pueblos y a la naturaleza. De esta manera, a partir del cuestionamiento del regionalismo abierto de 
los años noventa, se pretendía reducir las asimetrías entre los países y coadyuvar a la construcción de una comunidad internacional armónica y complementaria que conduzca a un verdadero multilateralismo. En consonancia con la tendencia regional y dada la mayor autonomía en su PE, Bolivia adhirió a un regionalismo posliberal, caracterizado por la búsqueda de autonomía, que pretende ir más allá de la dimensión económica y evitar la injerencia de los mercados y los actores estatales externos en las políticas de desarrollo y las respectivas políticas exteriores (Canelas y Verdes, 2011, p. 250). Desde el 2006, el país andino ha participado de forma activa en diversos ámbitos regionales como ALBA, UNASUR, CELAC y MERCOSUR.

Cabe destacar que la agenda pasó a estar definida por las prioridades fijadas por el Estado y por la identificación de las áreas consideradas como prioritarias. Se pueden mencionar como temas de la nueva agenda exterior, desde 2006, aquellos relacionados con

la lucha anticolonial y el derecho a la autodeterminación de los pueblos, los derechos de los pueblos indígenas, los derechos humanos fundamentales, los derechos de la naturaleza, el establecimiento de un nuevo orden económico mundial más justo y equitativo, la importancia de la cooperación mutua entre los países del Sur, la lucha por la paz y el desarme, el protagonismo de los movimientos populares y el derecho boliviano a una salida al mar (Paz Rada, 2018, p. 56).

Aquí cobra relevancia la influencia del cambio de narrativa, como plantea Malacalza (2020), sobre la construcción de discurso y de la PE de un país. A partir de la refundación del Estado iniciada por el MAS, se vislumbra un giro narrativo que influyó en la PE del país andino. Si se consideran los cambios en la PE que se propusieron, en el PND y en la nueva Constitución Política del Estado ${ }^{7}$ (promulgada en 2009), se observa - como se indicó previamente - que el MAS le otorgó un nuevo rol a la cooperación internacional (CI) y a la ayuda externa recibida dentro de la nueva estrategia de inserción internacional que se planteó, operando nuevamente a través de una narrativa diferente a la del pasado. Siguiendo a Lorenzini y Ceppi (2013),

en conjunto, los elementos de cambio mencionados determinan nuevos roles del Estado y de la CI en cuestiones fundamentales como los objetivos de desarrollo al que apuntan, el destino de los recursos, y los roles atribuidos a ambos actores en el proceso de diseño de las políticas públicas (p. 195).

De acuerdo a las directrices establecidas por el Ministerio de Planificación y Desarrollo, la gestión de la CI tendía a: transformar el rol del Estado garantizando la participación y control social sobre la gestión pública; transformar el patrón de desarrollo; y reducir las desigualdades, entre otras cuestiones. (Ministerio de Planificación y Desarrollo de Bolivia, 2013)

\footnotetext{
${ }^{7}$ La nueva Constitución plantea una nueva visión del estado promotora de un país multiétnico y plurinacional e identificando la soberanía del estado boliviano como eje fundamental de las relaciones internacionales a todo nivel. El texto constitucional también establece que el estado boliviano es independiente en las decisiones de política económica, sin aceptar imposiciones ni condicionamientos de parte de bancos, instituciones financieras, y entidades multilaterales o empresas transnacionales.
} 
La holgura fiscal resultante de la bonanza económica y los precios altos de las commodities sería lo que, en última instancia, le permitió al país que los objetivos de soberanía e independencia fueran plausibles. Ello repercutió no solo en el papel de la CI y en la estrategia de relacionamiento externo de Bolivia, sino también en el rol otorgado a la inversión pública.

Tal es así, que en el período 1999-2005 la inversión pública financiada con recursos externos alcanzó un promedio de $55 \%$, en tanto que en el período 2006-2012, esta proporción se ha reducido a 31\%. Esta relación se hace aún más pronunciada, si se considera que los valores absolutos de la inversión pública se han incrementado de \$us629 millones en 2005 a \$us2,874 millones en 2012 (Ministerio de Planificación y Desarrollo de Bolivia, 2013, p. 7).

En el marco del Ministerio de Relaciones Exteriores, también se observaron modificaciones en torno a las nuevas concepciones de PE y CI mediante la creación de Direcciones específicas para fomentar las relaciones entre los pueblos indígenas y la Cooperación Sur-Sur y la conformación de los Viceministerios de Coordinación con los Movimientos Sociales y de Descolonización. Por su parte, el Ministerio de Planificación y Desarrollo - principalmente con su Viceministerio de Inversión Pública y Financiamiento Externo - desempeñó un rol sobresaliente en todo este proceso.

\section{La Cooperación Internacional de Bolivia a raíz de los cambios externos}

Además de los factores domésticos - señalados anteriormente - el contexto internacional también marcó las pautas de cambio en la CI de Bolivia, especialmente con relación al Régimen de la Cooperación al Desarrollo a través del accionar del Comité de Ayuda al Desarrollo (CAD) de la Organización para la Cooperación y el Desarrollo Económicos (OCDE).

A principios del siglo XXI, la arquitectura de este régimen experimentó transformaciones y empezaron a discutirse los puntos negativos de la eficacia de la Ayuda Oficial al Desarrollo (AOD $)^{8}$. Entre los mismos se puede mencionar la volatilidad de los flujos y la fragmentación (de temáticas, de actores, de solapamiento de iniciativas y de falta de coherencia en las intervenciones). Estos temas se fueron tratando en las diferentes conferencias $^{9}$ de la Agenda de la Eficacia de la Ayuda, entre las cuales se destaca aquella

\footnotetext{
${ }^{8}$ Vale aclarar que la AOD es un componente de lo que se conoce como financiamiento externo, pero no el único, ya que existen otras fuentes de financiamiento públicas y privadas. La Cooperación Sur-Sur (CSS) tampoco entra dentro de la conceptualización de la AOD de la OCDE. La cooperación para el desarrollo tradicional es la que se enmarca en el seno del CAD/OCDE y se la conoce bajo la denominación de "Ayuda Oficial al Desarrollo" (AOD). Tanto esta categoría como la de CSS, junto a otros esfuerzos de cooperación regional o internacional que contribuyen a la creación o fortalecimientos de bienes públicos globales conforman la categoría más amplia de cooperación para el desarrollo.

${ }^{9}$ Los encuentros de principio de siglo XXII en los cuales se empieza a discutir una nueva arquitectura de la $\mathrm{Cl}$ fueron: Consenso de Monterrey (marzo de 2002); Foro de alto nivel sobre Armonización: Declaración de Roma (febrero de 2003); Mesa Redonda sobre la gestión de la financiación para el desarrollo basada en resultados (Marrakech 2004); Foro de alto nivel sobre la Eficacia de la Ayuda: Declaración de París (marzo de
} 
realizada en París en 2005 donde se reconocieron los problemas de la fragmentación y fatiga de la ayuda y la necesidad de nuevos acuerdos entre donantes y receptores, la problemática de las condicionalidades y el impacto de la Cooperación Sur-Sur (CSS) y los Países de Renta Media.

Antes de avanzar conviene realizar una breve descripción de la clasificación de país de renta media (PRM). Este criterio se le asigna a cada Estado de acuerdo al nivel de ingreso de cada economía, es decir, según el valor del Producto Bruto Interno per cápita de un país. Esta caracterización proviene del Banco Mundial (BM) y la OCDE para determinar el grado de elegibilidad de un país como potencial receptor de AOD. Utilizando esta división, aquellos países que registren ingresos per cápita medianos o mediano-altos no serían potenciales candidatos para recibir AOD (Olivera, 2013, p. 40).

Diversas discusiones surgieron en ambientes académicos y políticos en torno a este concepto ya que la medida propuesta es pensada desde una lógica economicista y no considera otros parámetros, como el bienestar de los habitantes ni el grado de desarrollo de un país ni la desigualdad presente en el mismo. Por lo tanto, para muchos países esta categoría resulta insuficiente como medida para establecer los flujos de la ayuda internacional. Por otro lado,

la caracterización de la mayoría de América Latina como países de renta media, en el contexto de una estrategia global de focalización de los fondos de AOD en torno a la reducción de la pobreza, ha significado una disminución sensible de dichos financiamientos y, sobre todo, en términos simbólicos la pérdida de centralidad de América Latina como participantes del grupo de países en vías de desarrollo (Pattacini, 2013, p. 30).

En este sentido los países latinoamericanos asumen un rol dual en tanto solicitantes y dadores de CI involucrándose como actores proactivos del régimen de la cooperación al desarrollo.

La Agenda de la Eficacia de la Ayuda, al estar dominada por los países donantes y del "Norte", se la concibe desde el "Sur", especialmente desde América Latina, como poco relevante. Los principios fijados en París por la OCDE pretendían:

orientar a la comunidad de cooperantes en la superación de los problemas y falta de apropiación de los países beneficiarios, la falta de alineamiento de las prioridades de cooperantes con las prioridades de los gobiernos nacionales, la falta de coordinación o armonización entre cooperantes en el terreno, la falta de rendición de cuentas mutua y las debilidades de gestiones poco orientadas a resultados (Alemany y Freres, 2018, p. 61).

Desde la Declaración de París de 2005 hasta la Conferencia en Busan de 2011, el foco estuvo centrado en conceptos como armonización, alineación, rendición de cuentas, gestión en base a resultados, así como el nuevo ímpetu hacia la CSS. Así, el paradigma de buscar la efectividad de la ayuda ha sido sustituido por la efectividad del desarrollo, reflejando un

2005); Foro de alto nivel sobre la Eficacia de la Ayuda: Accra (septiembre de 2008); Conferencia de Seguimiento sobre la Financiación para el Desarrollo, Doha (diciembre de 2008); Foro de Alto Nivel sobre la Eficacia de la Ayuda en Busan (2011), solo por mencionar los principales. 
avance integral en la concepción de una verdadera asociación entre países que va más allá de flujos financieros e incorpora nuevos retos respecto a la coherencia de políticas que afectan las relaciones bilaterales y el surgimiento de nuevos actores (Ministerio de Planificación y Desarrollo de Bolivia, 2013). Esta nueva visión quedó instituida en la Asociación Global para una Efectiva Cooperación al Desarrollo creada en Busan.

Es importante recordar que desde los noventa la región latinoamericana ya no era prioritaria para los miembros del CAD;

desde entonces, los donantes han destinado en general menos del 10\% de su AOD a los países latinoamericanos, de tal manera que en 2015 esta región recibió apenas el 6,6\% de la AOD total, frente a los $28 \%$ que fueron para África, 13\% para Asia y 12\% para Medio Oriente (Alemany y Freres, 2018, p. 67).

A principios del siglo XXI, la agenda mundial de desarrollo se enmarcó en la Declaración del Milenio aprobada por la Asamblea General de ONU en 2000. Un año más tarde el Secretario General del Organismo propuso los Objetivos de Desarrollo del Milenio (ODM) con el año 2015 como fecha de cumplimiento. Éstos configuraron la Agenda del Milenio, importante también en la evolución del Régimen de la Ayuda y resultó ser el puntapié de un nuevo debate sobre políticas, actores y gobernanza de la CI al desarrollo (Sanahuja y Tezanos Vásquez, 2017, p. 534).

La adopción de los ODM supuso una diversificación de la agenda dando mayor importancia a los derechos económicos y sociales. De esta manera, los mismos buscaban relegitimar la AOD al vincularla con la lucha contra la pobreza y, en consecuencia, se reasignaba recursos financieros a los países más pobres. "Supone en concreto mayor financiación para los países pobres y, sobre todo, ampliar sus oportunidades de desarrollo en ámbitos como el comercio, la inversión, las migraciones, la sostenibilidad ambiental, la paz y la seguridad internacional” (Sanahuja y Tezanos Vásquez, 2017, p. 536)

Sin embargo, las metas planteadas resultaron insuficientes y no lograron alcanzar las expectativas fijadas. Asimismo, es necesario añadir, la crisis de los países desarrollados especialmente a partir de la crisis financiera de 2008 - y el ascenso de los países emergentes. Ello transformó el escenario internacional al mismo tiempo que modificó la tradicional relación Norte-Sur y las tradicionales dinámicas entre donantes y receptores de la AOD. Como consecuencia resurge el "Sur Global" y el liderazgo del desarrollo se desplaza hacia otros actores.

En este contexto surge la Agenda 2030 y la creación de los Objetivos de Desarrollo Sostenible (ODS). Los cambios descritos se encuentran en las nuevas metas al desarrollo aprobadas por la Asamblea General de ONU en 2015. Con estos nuevos objetivos se relegitima la AOD y se abre un nuevo escenario o, siguiendo la terminología utilizada por Montúfar (2004), se podría decir que se conforma un nuevo modelo interpretativo de la ayuda. Desde ese momento, se sostiene que la Agenda del desarrollo global "deviene agenda universal que afecta a las políticas nacionales e incluso a los estilos de vida no sostenibles vigentes tanto en los países ricos como en los emergentes" (Sanahuja y Tezanos Vásquez, 2017, p. 539).

En América Latina han existido visiones propias en torno a los modelos de desarrollo y a la CI: algunas legitimando o reconociendo la necesidad de la ayuda, otras planteando la 
necesidad de propuestas alternativas desde la región y, otras, ignorando el sistema, no legitimando los espacios propuestos por la OCDE. Sin embargo, desde la región se ha aportado a la configuración misma de la Agenda a nivel internacional, principalmente en el seno de Naciones Unidas (ONU), jugando un papel relevante en la redefinición de formas y enfoques de relacionamiento entre países del Sur a favor del desarrollo. En este sentido, vale la pena resaltar que dicha agenda convive con visiones alternativas de desarrollo como el Vivir Bien planteado desde Bolivia, a pesar de las contradicciones que puedan existir entre cada uno de estos modelos.

El paradigma del Vivir Bien fue recuperado por el MAS y su proyecto político. Se plantea como un paradigma filosófico rescatado de los pueblos indígenas y es entendido como un proceso, como una nueva forma de plantear la relación Estado-sociedad y Estadoeconomía. Esta perspectiva implica transformaciones profundas en la concepción de desarrollo occidental ya que las políticas públicas de dicho modelo y los principios del liberalismo económico no han puesto foco en planes que se orienten a reducir las asimetrías sociales y a mejorar la calidad de vida de la población, entendiéndola como un todo (Martínez, 2016, p. 15). El modelo de desarrollo occidental está asociado a la producción de bienes, con la riqueza y es inherente al "Vivir Mejor", generando asimetrías en los estándares de vida entre los Estados. En cambio, el Vivir Bien ${ }^{10}$ busca el equilibrio, la armonía, el consenso y la complementariedad.

En Bolivia, el Vivir Bien no sólo es un concepto, un paradigma, es también una alternativa política que se ha ido desarrollando en el proceso de reconstrucción de la memoria, la cosmovisión, y las estructuras de autoridad originaria en varios núcleos del pensamiento y del activismo político [...] Este paradigma, en el caso boliviano, es el norte orientador para la construcción del Estado Plurinacional y la puesta en marcha de un modelo de economía plural, holístico, que rompa con la visión capitalista de desarrollo asentada en el extractivismo y en la enajenación de nuestros recursos naturales (Romero y Lanza, 2012, p. 55).

La Agenda de Desarrollo en el país andino - desde la llegada del MAS al poder- estuvo enmarcada, en primer lugar, por el PND 2006-2011 descrito anteriormente. Luego se sumó al mismo, el Plan de Desarrollo Económico y Social 2016-2020 (PDES) y la Agenda Patriótica 2025. En el planteamiento de estos planes se observa la materialización del Vivir Bien y del patrón de desarrollo impulsado por el gobierno del MAS.

En Bolivia se observa un alineamiento de la Agenda Patriótica ${ }^{11}$ y los Planes de Desarrollo con los ODS. Si bien en dicha Agenda no hay una mención explícita a la Agenda

\footnotetext{
${ }^{10}$ Para más información sobre el Vivir Bien consultar Huanacuni Mamani, Fernando (2015). Vivir Bien/Buen Vivir. Filosofía, políticas, estrategias y experiencias de los pueblos ancestrales. La Paz, Ed. CAOI.

11 Los principios de la Agenda Patriótica son: 1. Erradicación de la extrema pobreza; 2. Socialización y universalización de los servicios básicos con soberanía para Vivir Bien; 3. Salud, educación y deporte para la formación de un ser humano integral; 4. Soberanía científica y tecnológica con identidad propia; 5. Soberanía comunitaria financiera; 6 . Soberanía Productiva con diversificación y desarrollo integral sin la dictadura del mercado capitalista; 7. Soberanía sobre los recursos naturales, con nacionalización, industrialización y comercialización en armonía y equilibrio con la Madre Tierra; 8. Soberanía alimentaria a través de la construcción del saber alimentarse para Vivir Bien; 9. Soberanía ambiental con desarrollo Madre Tierra; 10. Integración complementaria de los pueblos con soberanía; 11. Soberanía y transparencia en la gestión pública
} 
2030, del análisis de sus pilares se puede observar el alineamiento de los mismos con los ODS. Estos documentos se enmarcan en la nueva Constitución Política del Estado (CPE) estableciendo el marco normativo a partir del cual interpretar el rol de la CI en la configuración del Estado Plurinacional de Bolivia.

Los espacios multilaterales, en especial, Naciones Unidas, han sido aprovechados por Evo Morales para difundir los principios de la PE del MAS. Es por ello que resulta interesante mencionar algunas acciones que dan cuenta del alineamiento del gobierno masista con los ODS y el compromiso para alcanzarlos.

El primer hito a mencionar es el establecimiento del día 22 de abril como Día Internacional de la Madre Tierra, en la 80ª sesión plenaria de 2009 de la Asamblea General de ONU. En esta ocasión, el presidente Morales invitó a los participantes a reflexionar sobre la importancia del cuidado de la naturaleza, reconociendo que el siglo XXI debería ser el siglo de los Derechos de la Madre Tierra. Asimismo, propuso cuatro derechos importantes para la humanidad: el derecho a la vida; el derecho a la regeneración de la biodiversidad; el derecho a una vida limpia sin contaminación y el derecho a la armonía y equilibrio entre todos y todas.

Una de las temáticas que se relaciona con el punto anterior y que también ha sido defendida por el presidente boliviano en los foros internacionales es el cambio climático, sus consecuencias y la necesidad de encontrar soluciones. Luego del fracaso de la $15^{\circ}$ Conferencia sobre el Cambio Climático en Copenhague en el año 2009, Evo Morales convocó en 2010 a una Conferencia Mundial de los Pueblos sobre el Cambio Climático y defensa de la vida que se realizó en el mes de abril de ese año en Tiquipaya, Cochabamba. Estuvieron presentes representantes de más de 140 países, 90 delegaciones oficiales y numerosos grupos y movimientos sociales.

Asimismo, en el $108^{\circ}$ plenario de la Asamblea General de ONU, Bolivia presentó un proyecto para reconocer el acceso al agua potable y al saneamiento como un derecho humano. El mismo fue aprobado por 122 países e impulsaba a los Estados y a las organizaciones internacionales a que destinen recursos financieros a fin de intensificar los esfuerzos para proporcionar a toda la población un acceso económico al agua potable y al saneamiento en tanto un derecho humano esencial.

Luego, en 2015, Bolivia consiguió que desde ONU se reconozcan unánimemente los principios ancestrales andinos Ama Sua (no seas ladrón), Ama Llulla (no seas mentiroso) y Ama Quella (no seas flojo) en el marco de la promoción de una gestión pública eficiente y transparente. Estos principios del Vivir Bien, reconocidos en la CPE, fueron la base fundamental para la implementación de la Agenda 2030. (Sistema de Naciones Unidas, 2018, p. 2)

\footnotetext{
bajo los principios de no mentir, no robar y no ser flojo; 12. Disfrute y felicidad plena de nuestras fiestas, nuestra música, nuestros ríos, nuestra selva, nuestras montañas, nuestros nevados, de nuestro aire limpio, de nuestros sueños; 13 . Reencuentro soberano con nuestra alegría, felicidad, prosperidad y nuestro mar.
} 
Por otro lado, cabe destacar que entre Bolivia y ONU se ha firmado en tres oportunidades el Marco de Asistencia de las Naciones Unidas para el Desarrollo ${ }^{12}$ (UNDAF), convirtiéndose en el marco estratégico de programación que describe la respuesta colectiva y el compromiso de trabajo del sistema de la mencionada organización con las prioridades nacionales de desarrollo bajo un enfoque que "incorpora tres principios programáticos: (1) Derechos Humanos y No dejar a nadie atrás, (2) Desarrollo sostenible y resiliencia y (3) Transversalización del enfoque de género; y tres ejes transversales: (1) Voluntariado, (2) Fortalecimiento de bases de datos y (3) Cooperación Sur- Sur" (UNDAF, 2017, p. 9).

Este Acuerdo Marco, bajo el liderazgo del Ministerio de Planificación y Desarrollo, refleja el compromiso de Bolivia con el desarrollo sostenible y las acciones globales que ONU proyecta.

Esto se hace manifiesto en el desarrollo y la implementación de programas y proyectos focalizados y dirigidos a reducir la pobreza y brechas de desigualdad. También en promover un modelo de desarrollo incluyente, equitativo y sostenible que garantice el ejercicio y la exigibilidad de los bolivianos al derecho de vivir bien (UNDAF, 2017, p. 20).

Asimismo, otro hecho que tuvo un impacto significativo fue la inclusión de Bolivia como país de renta media (PRM) baja por el Banco Mundial en el año 2010. La nueva clasificación del país determinó a su vez la migración hacia instrumentos de financiamiento menos concesionales, como son los créditos comerciales, más comunes en países de renta media.

De acuerdo a datos publicados por el Banco Mundial, "los recursos de AOD a Bolivia tuvieron una tendencia decreciente tanto en términos absolutos y relativos como en la participación del país en la AOD total a nivel regional y mundial. Entre 2006 y 2013 la AOD se redujo de 7,4 a 2,3 por ciento del PIB" (Paz Arauco, 2014, p. 1). Este contexto de disminución de la AOD recibida confluyó al mismo tiempo con un nuevo ímpetu hacia la CSS como estrategia a seguir por parte del gobierno boliviano.

\section{Narrativa de la Cooperación Sur-Sur en el siglo XXI y su influencia en Bolivia}

El nuevo rol desplegado por los países de América Latina en relación al Sistema de CI a partir de la Agenda 2030, previamente señalado, permitió visibilizar la relevancia de los esquemas de CSS en el logro de las metas establecidas por la comunidad internacional. Los países emprendieron acciones para alinear las actuaciones de CSS a los ODS, como se describió en el caso de Bolivia. También se reforzó la Cooperación Triangular como modalidad estratégica para las relaciones Norte-Sur. Esto coincidió con el período de disminución de los recursos destinados desde los países del Norte para la ayuda externa, a causa, entre otros elementos, de la crisis económica que los mismos atravesaban desde 2008.

\footnotetext{
12 El Marco UNDAF que en el país adopta el nombre de "Marco de Complementariedad de Naciones Unidas para el Vivir Bien en Bolivia", se ha firmado para los períodos 2008-2012; 2013 - 2017 y 2018- 2022.
} 
De esta manera, resurgió ${ }^{13}$ la CSS y cobró relevancia en la PE de los países en desarrollo a principios del siglo XXI, ya sea por fines solidarios o para satisfacer los intereses nacionales de los oferentes, en busca del desarrollo mutuo. Desde la lógica del Sur, la cooperación se consideraba como una actividad asociativa con objetivos de desarrollo compartidos y no desde una lógica vertical y asistencialista como se la valoraba desde el Norte. De esta manera, se generaron espacios de cooperación diferentes a la AOD a partir del rol dual de los países del Sur como receptores y oferentes de CI para el desarrollo. Este tipo de cooperación cuestionaba las relaciones de poder, la legitimidad, la normatividad y la gobernanza de la cooperación Norte-Sur (Lechini y Morasso, 2015, p. 121).

La Cooperación Sur-Sur es un concepto multifacético, controvertido y ampliamente debatido, por lo que resulta difícil encontrar una definición unánime del mismo. En este trabajo se toma en consideración la definición realizada por Lechini (2009) quien establece que la CSS

refiere de modo general a una cooperación política que apunta a reforzar las relaciones bilaterales y/o a formar coaliciones en los foros multilaterales, para obtener un mayor poder de negociación conjunto, en defensa de sus intereses. Se basa en el supuesto que es posible crear una conciencia cooperativa que les permita a los países del Sur reforzar su capacidad de negociación con el Norte, a través de la adquisición de mayores márgenes de maniobra internacional y con ellos, mayor autonomía decisional, para afrontar y resolver los problemas comunes (p. 67).

La CSS ha adoptado diversas modalidades y se ha desarrollado de manera bilateral, regional o en combinación con esquemas de Cooperación Triangular. De las formas más usuales establecidas, se encuentra la asistencia técnica bilateral. "Empero, la CSS bilateral también incluye acciones directas de desarrollo social; la asistencia financiera; y la cooperación en materia de energía" (Sanahuja, 2011, p. 214).

También resulta necesario incluir en la conceptualización de la CSS el concepto de Cooperación Sur-Sur para el Desarrollo (CSSD) ya que "permite diferenciar esta dimensión de las relaciones Sur-Sur como un área específica de políticas que comprende la promoción y/o la colaboración en la construcción de capacidades entre países en desarrollo" (Malacalza, 2020, p. 4). En los Informes de la Secretaría General Iberoamericana (SEGIB) ${ }^{14}$, se resalta el rol desempeñado por los países de América Latina en este tipo de cooperación y entre los propósitos de los proyectos de la región se subraya el fortalecimiento de las economías y la realización de programas sociales e institucionales (Lechini y Morasso, 2015, p. 122).

Se desprende de esta caracterización que la CSS es retomada como una herramienta de política exterior y de desarrollo de los países de América Latina. A partir de la misma se realiza un entramado de relaciones entre los países de manera complementaria cuyo eje es el establecimiento de objetivos de desarrollo para las partes involucradas.

\footnotetext{
${ }^{13}$ El origen de la CSS puede remontarse a la Conferencia de Bandung (1955) y al Movimiento de No Alineados. A comienzos del siglo XXI, la CSS resurge en un contexto que recordaba al de la década del setenta: países de África, Asia y América Latina que luchaban por incidir en las reglas de juego del sistema internacional para mejorar su status periférico. (Lechini, G. y Morasso, C., 2015, p. 116)

${ }^{14}$ Los Informes de la SEGIB están disponibles en su página web: https://www.segib.org/
} 
Es por todo lo expuesto que la CSS cobra gran importancia para los PRM y para América Latina, en especial, teniendo en cuenta el contexto de su resurgimiento. Desde las partes involucradas se observa el convencimiento de los beneficios que este tipo de cooperación genera al actuar como mecanismo de legitimidad discursiva y permitir convertirse en actores globales y poseer un status diferente en el sistema internacional. Entre sus beneficios se pueden mencionar "capacidades institucionales y tecnológicas, inversiones, acceso a mercados o internacionalización de sus empresas. Según los países involucrados, pueden adecuarse mejor a sus necesidades dado que hace mayor uso de recursos locales, y genera un mayor sentido de apropiación (ownership)" (Sanahuja, 2011, p. 216).

La preferencia por esquemas de CSS se observa en toda la región latinoamericana, caracterizada por la coincidencia político-ideológica de muchos de sus gobiernos progresistas o el "giro a la izquierda" antes mencionado; un ciclo económico de bonanza de los precios de las materias primas; políticas económicas con carácter soberanista; aumento de la inversión en el comercio Sur-Sur intrarregional y con otras regiones del Sur; la relativa ausencia de Estados Unidos y los renovados vínculos con los BRICS.

Se puede inducir que el crecimiento económico de la región supuso un aumento de los recursos, los cuales fueron empleados para financiar las políticas nacionales de desarrollo, la inversión interna e implementación de políticas sociales, como también llevar adelante estrategias de integración regional. Se percibía que en la región se "había definido un espacio más autónomo con relación a la narrativa dominante de los países de la OCDE y el sistema de Bretton Woods y promovió nuevas plataformas de articulación política en este sentido como la UNASUR o la CELAC en 2004 y 2011, respectivamente" (Alemany y Freres, 2018, p. 66)

El contexto que se viene desarrollando manifiesta, entre otros factores, la inclinación de la ayuda externa recibida por Bolivia hacia esquemas de CSS a partir de los primeros años del siglo XXI.

Otro elemento explicativo de ese cambio se encuentra en la conflictiva relación con los Estados Unidos. Los primeros desacuerdos se dieron cuando Evo Morales declaró en 2008 persona non grata a Philip Goldberg, Embajador de Estados Unidos en La Paz, por reunirse con la oposición y entrometerse en los asuntos internos del país. Sumado a lo anterior, se tomó la decisión de suspender las actividades del Departamento Antidrogas de EEUU (DEA), acusada de realizar tareas de inteligencia política bajo el paraguas de la lucha contra el narcotráfico. Luego cuando en 2013 el presidente boliviano expulsó del país a la Agencia de Estados Unidos para el Desarrollo Internacional (USAID), al acusarla de injerencia política y de conspirar contra su gobierno, marcó un punto de inflexión en la relación bilateral y este hecho fue presentado como paradigmático del principio soberanista de la PE durante el Gobierno de Morales.

A continuación, se hará una breve mención a algunos ejemplos ${ }^{15}$ que configuran la nueva narrativa, el nuevo marco normativo y destacan los actores, sectores y fuentes de financiamiento involucrados de la CSS en Bolivia.

\footnotetext{
${ }^{15}$ Escapa a los fines de este trabajo realizar una descripción exhaustiva y completa de todos los casos de cooperación internacional de Bolivia. Se mencionan algunos que se consideran paradigmáticos o
} 
Como parte de las políticas del gobierno boliviano y de las decisiones tomadas por el presidente Evo Morales con relación a la CSS, la implementación de la Diplomacia de los Pueblos se torna fundamental ya que la misma incorporó a las organizaciones indígenas y populares a las actividades internacionales del país. A su vez, fue importante la participación de Bolivia en los proyectos integracionistas del ALBA, la UNASUR y la CELAC ya mencionados. Es necesario destacar que Bolivia presentó en el marco del ALBA, el Tratado de Comercio de los Pueblos (TCP) como un aporte para una relación comercial, económica y política de tipo horizontal y complementaria entre los países en el marco de la CSS (Paz Rada, 2018, p. 55).

Otro accionar del país andino a destacar es la Cumbre del G-77+China que se organizó, en junio de 2014 en Santa Cruz en el marco de la celebración de los cincuenta años de la creación del Grupo de los 77 dentro de Naciones Unidas. Esta Cumbre que se realizó bajo los principios de la CSS permitió a Evo Morales reafirmar la postura de Bolivia. Otro evento a subrayar, también realizado en este último país, fue la Cumbre de los Movimientos Sociales y Populares en julio de 2015, con la presencia del Papa Francisco, dirigentes obreros y campesinos de todas las regiones del mundo.

Por otro lado, de los principales socios en relación a la CSS que se pueden mencionar del gobierno del MAS, se destacan Venezuela y Cuba (tanto en las relaciones bilaterales como en torno al ALBA), Argentina, y algunos casos de triangulación con España.

Tomando como referencia los primeros años de gobierno, "entre 2007 y 2009, la CSS de Cuba y Venezuela - y en menor medida de otros países - posibilitó que Bolivia se transformara en el receptor de más del $35 \%$ de las actividades sociales, en especial en materia de salud y educación" (Lorenzini y Ceppi, 2013, p. 202).

Ejemplo en materia de educación es el Programa "Yo, sí puedo" con Cuba cuyo fin fue reducir al máximo posible el número de población analfabeta o subescolarizada mediante el uso de medios de comunicación masiva. Venezuela también financió mediante la Misión Robinson Internacional, durante 2006 y 2008, con recursos humanos y financieros que luego se incorporaron al Método "Yo, sí puedo". En relación al ámbito de la salud a través de la "Operación Milagro", Cuba ofreció atención oftalmológica gratuita a personas de bajos recursos (Paz Rada, 2018, p. 59).

Por su parte Venezuela, operó en Bolivia por medio de las Misiones Sociales que principalmente se basaron en: atención gratuita de médicos, becas estudiantiles en educación superior; y la Misión Moto Méndez en la que participó también Cuba para asistir a personas con discapacidades físicas e intelectuales (Lorenzini y Ceppi, 2013, p. 205).

También se puede señalar como otro proyecto de CSS entre Venezuela y Bolivia el Programa "Bolivia cambia, Evo cumple", destinado a dar respuesta a las demandas de servicios básicos como agua potable, saneamiento, centros médicos, aulas, electrificación, espacios de esparcimiento, entre otros. Resulta interesante mencionar que este Programa, iniciado en 2007, fue diseñado en el marco del PND. "Desde sus inicios y hasta julio de 2011, los fondos fueron suministrados por la República Bolivariana de Venezuela y el

ejemplificadores y de los cuales se cuenta con información. En este sentido, en el presente trabajo no se analizan todas las dimensiones o acciones de la PE boliviana y el caso concreto de las relaciones bilaterales será abordado en profundidad en futuras investigaciones. 
ALBA. A partir de mediados de 2011 Morales estableció la continuidad del programa que se financiaría con fondos provenientes del Tesoro Nacional" (Lorenzini y Ceppi, 2013, p. 205).

En referencia a la relación entre Bolivia y Argentina, muchas de las acciones se canalizaron a través del Fondo Argentino de Cooperación Horizontal (FO-AR), programa de la Cancillería Argentina que brinda cooperación técnica a países de igual o menor desarrollo relativo económico y social, con el objeto de contribuir al crecimiento de los países y su población. Las áreas temáticas en las que más se ha cooperado durante los primeros años del gobierno del MAS se relacionan con el fortalecimiento institucional de la administración pública, agroindustria, innovación tecnológica, derechos humanos y salud. Por otro lado, además de los proyectos bilaterales, existen tres iniciativas ${ }^{16}$ triangulares cuyos socios son la Agencia Española de Cooperación Internacional para el Desarrollo y la Agencia de Cooperación Alemana (FO-AR, 2019).

Del detalle expuesto, se deprende que el país andino ejerce mayoritariamente un rol de receptor de instancias de CSS bilateral y Cooperación Triangular. De acuerdo a la SEGIB,

en 2017 Bolivia participó en un total de 125 acciones, proyectos y programas de Cooperación Sur-Sur. En la mitad de las ocasiones (50,4\%), esas iniciativas fueron ejecutadas bajo la modalidad Bilateral, en un $26,4 \%$ bajo la Regional y en un 23,3 \% a través de la Triangular. Asimismo, ejerció mayoritariamente el rol de receptor en las iniciativas de CSS Bilateral (84\%) y Cooperación Triangular (100\%), principalmente en los sectores de Salud y Agropecuario. Desde el ejercicio del rol de oferente pudo fortalecer las capacidades y conocimientos de sus socios iberoamericanos en diversos sectores. En conjunto, su participación en la CSS de 2017, [...] contribuyó a alinear la cooperación de la región con el ODS 16, el ODS 11 y el ODS 3 (SEGIB, 2020, p. 181).

Respecto a los últimos años, América Latina experimentó cambios políticoideológicos significativos de algunos de sus gobiernos a lo que se sumó profundas crisis político-institucionales en muchos de ellos. En este sentido resulta relevante para Bolivia la agudización de la crisis multidimensional en Venezuela, teniendo en consideración que dicho país es - junto a Cuba - uno de sus principales socio clave en materia de cooperación internacional.

Este escenario confluyó en un nuevo proceso, de signo contrario al emprendido a principios de siglo. Asimismo, hay que tener en cuenta el fin de ciclo económico manifiesto en la caída del precio de las materias primas y el aumento del endeudamiento, entre otros factores.

En palabras de Paz Rada (2018), "los procesos de integración y de CSS se han debilitado sustancialmente con el viraje adoptado especialmente por los nuevos gobiernos

\footnotetext{
${ }^{16}$ Estas estrategias son: 1) Estrategias de control de la langosta voladora. 2) Sensibilización ambiental y aprovechamiento de residuos agrícolas de la cosecha de caña de azúcar. 3) Fortalecimiento de capacidades del sector vitivinícola para la gestión sostenible de los recursos de agua y energía (FO-AR, 2019).
} 
de Brasil y Argentina, así como por la presión de las políticas de Estados Unidos en los gobiernos sobre los que tiene mayor influencia" (p. 60).

Luego de la etapa de crecimiento de la CSS (2007-2013) en donde la tasa media de crecimiento anual de Proyectos y acciones de este tipo de cooperación fue del 7,8\%; durante la etapa posterior se detectó una retracción de las iniciativas cuando la tasa de aumento promedio se situó en un negativo $8,2 \%$.

Entre 2013 y 2016, la reducción en el volumen total de iniciativas intercambiadas ha estado acompañada de un cambio en su composición, y en una ganancia de espacio y peso relativo de los instrumentos de cooperación que tienen una mayor dimensión (los proyectos frente a las acciones en el caso de la Triangular; los programas frente a los proyectos en el caso de la Regional) (Rivero y Xalma, 2019, p. 14).

En cuanto al escenario global, se vislumbra la crisis de la globalización y de hegemonía, de la mano de la creciente disputa entre EEUU y China. Todo ello converge en un aumento de la polarización ideológica y de conflictos de intereses entre los países, trayendo como consecuencia un período de estancamiento e incertidumbre para la CSS que cobra un nuevo rol para algunos gobiernos, se estigmatiza y asocia a la corrupción, o es reemplazada por otros esquemas, e incluso hasta llega a desaparecer de la mayoría de los discursos presidenciales (Malacalza, 2020, p. 5).

Transcurridos los primeros quince años del siglo XXI, comenzó a percibirse una narrativa diferente que produjo un nuevo cambio en el marco interpretativo de la ayuda y de la CI no solo en la región, si no en el mundo entero. En este contexto, el protagonismo de Bolivia también ha decaído y el escenario externo volvió a repercutir sobre el rol otorgado a la CI por el gobierno masista. Sin embargo, se pueden identificar los principios de la CSS en el accionar del país andino en las instancias participativas del Movimiento de Países No Alineados (MNOAL), el G-77+China, el ALBA-TCP y los contactos bilaterales con países de Medio Oriente, Asia y África (Paz Rada, 2018, p. 60). Cabe destacar que su convulsionado y polarizado ámbito interno también influyó en la disminución del rol de Bolivia en el escenario internacional, y en el poco activismo de su PE y consecuentemente de su política de CI.

El nuevo escenario mencionado de los últimos años y su impacto en Latinoamérica sobre la CI en general y sobre la CSS en particular, también tuvo sus consecuencias en el acceso a la información y transparencia sobre los compromisos asumidos en materia de CI. En muchas ocasiones, los datos no se encuentran sistematizados o no son de público acceso. Como lo expresan Lechini y Morasso (2015) "es una cuestión compleja para los gobiernos justificar los fondos que se dedican a la cooperación internacional al desarrollo, aun cuando la misma se ejecuta en un contexto de solidaridad Sur-Sur y en función de los intereses nacionales" (p. 125). Bolivia no está exenta de este fenómeno y, por lo tanto, no es posible contar con información detallada como sí sucede con los primeros años del gobierno del MAS. La tarea de profundizar en estas cuestiones, especialmente en lo que respecta al último gobierno de Morales, será abordada en futuras investigaciones. 


\section{Reflexiones finales}

A lo largo del presente trabajo se ha realizado un recorrido sobre la evolución de la CI en Bolivia a partir de la llegada del MAS a la presidencia en 2006, con el propósito de vislumbrar la influencia de los factores domésticos e internacionales en el cambio de narrativa y el accionar de la PE del país y del sistema de Cooperación Internacional. De esta manera, se analizó el cambio de rol concedido a la CI durante los tres gobiernos de Evo Morales.

Se pudo distinguir que el proceso refundacional del Estado planteada por el MAS, inició un periodo de cambio interno en el país andino bajo un nuevo modelo de desarrollo que repercutió en su política interna y externa. Ello significó al mismo tiempo cambios normativos/institucionales, discursivos y de políticas que influyeron en los esquemas de ayuda externa y de CI percibidos por el país. Por otro lado, se detectó también que los hechos acontecidos a nivel del sistema internacional, específicamente en el Régimen de la Cooperación al Desarrollo impactaron en ese proceso.

Este escenario no fue exclusivo de Bolivia, sino que se percibió como un fenómeno regional. Entendiendo a la CSS como un proceso en construcción y considerando lo descrito en el trabajo, es importante destacar que el significado de este tipo de esquemas de cooperación representa distintas cosas según el interlocutor, por lo cual, no es posible encontrar un solo relato explicativo (Lechini, 2009, p. 77).

A principios del siglo XXI se asistió a un resurgimiento de los esquemas de CSS donde los países de América Latina contaron con mayores márgenes de maniobra y adquirieron un rol protagónico respecto a la participación dentro de la CSS y en la construcción de la Agenda 2030. Este proceso fue favorecido por la coincidencia político-ideológica de muchos de los gobiernos de la región y el boom de las commodities. Luego a partir de 2015, se divisó un nuevo panorama caracterizado por una crisis generalizada a nivel del sistema internacional - de la globalización y de hegemonía - y regional - ascenso de gobiernos conservadores/de derecha, crisis político-institucionales y declive económico -. Ello repercutió en el accionar externo de los gobiernos latinoamericanos, especialmente provocando una reorientación de sus políticas de cooperación.

Por su parte, el gobierno del MAS construyó una nueva narrativa ligada a un modelo de desarrollo sustentado en el Vivir Bien con un marco normativo-institucional diferente a la etapa anterior del país, que se conjugó con diferentes marcos interpretativos de la ayuda. Más allá del cambio de narrativa en todos los ámbitos, desde la llegada del MAS al poder, se observó una inclinación del gobierno hacia esquemas de CSS y se identificó la existencia de una agenda soberana de intervención y apropiación de las políticas de desarrollo por parte del estado (Paz Arauco, 2014, p. 8). Sin embargo, al mismo tiempo se detectaron matices, ya que Bolivia continuó participando de las reglas y principios planteados desde el Régimen de la Ayuda y la Agenda 2030 con la cual se encuentra comprometida en su cumplimiento. Por otro lado, el gobierno reconoció que seguía recibiendo fondos tradicionales, de los esquemas Norte-Sur dadas las condiciones estructurales del país entendiendo que la aceptación de la ayuda posibilitaba mejorar el bienestar de la población (Lorenzini y Ceppi, 2013, p. 197) y alcanzar los objetivos de desarrollo. 
Sin dudas, con el gobierno del MAS, Bolivia ha logrado mayor autonomía y activismo en el escenario internacional. En base al análisis realizado, se podría concluir que el gobierno de Evo Morales actuó desde una perspectiva narrativa de la CI siguiendo lo expresado por Malacalza (2014, p. 170) ya que las percepciones, creencias y discursos moldearon una nueva identidad del estado boliviano dando como resultado una nueva política de cooperación para el desarrollo efecto de una construcción narrativa diferente producto de un contexto histórico específico.

Teniendo en cuenta el panorama actual del sistema internacional - afectado por la pandemia - y el de Bolivia en particular - instauración de un nuevo gobierno del MAS luego de una profunda crisis político e institucional -, para finalizar y a modo de reflexión para futuros trabajos se plantean los siguientes interrogantes: ¿Cuál será el marco epistemológico a partir del cual se sustentará el Sistema de Cooperación Internacional?; ¿Qué características tendrá el modelo interpretativo de la AOD en el mundo post-pandemia?; ¿Cómo influirán esos nuevos escenarios en la región latinoamericana y en especial en Bolivia, teniendo en cuenta que los intereses de los donantes cambiarán?; ¿Podrán los esquemas de CSS sobrevivir y plantear espacios de acción concretos? Seguramente una nueva narrativa se está escribiendo y con ella una reconfiguración de la ayuda externa y de los esquemas de cooperación se desarrollará en los próximos años. Resta esperar para poder observar la influencia del escenario actual en Bolivia bajo un nuevo liderazgo del MAS en el poder.

\section{Referencias Bibliográficas}

ALEMANY, C. Y FRERES, C. (2018). América Latina en busca de una inserción efectiva en la agenda internacional de la cooperación para el desarrollo. Revista Internacional de Cooperación y Desarrollo, 5(1), pp. 59-84. https://doi.org/10.21500/23825014.3596

CANELAS, M., Y VERDES, F. (2011). La nueva política exterior boliviana (2005-2010): más autonomía y nuevos desafíos. En Errejón, I. y A. Serrano, A. (eds.), ;Ahora es cuándo, carajo!, del asalto a la transformación del Estado en Bolivia, pp. 239-266. Barcelona, España. El Viejo Topo.

CUNHA FILHO, C. (2016). Estrategias de desarrollo e inserción internacional en la Bolivia de Evo Morales. Revista Andina de Estudios Políticos, pp. 146-162. Recuperado de https://www.iepa.org.pe/raep/index.php/ojs/article/view/83/55

DO ALTO, H. (2008). El MAS-IPSP boliviano, entre movimiento social y partido político. Revista de Análisis Político, pp. 25-46. Recuperado de http://www.scielo.org.co/pdf/anpol/v21n62/v21n62a02.pdf

FO-AR. (2019). Informe de la Cooperación Sur-Sur y Triangular. Dirección General de Cooperación Internacional (DGCIN). Ministerio de Relaciones Exteriores y Culto de la República Argentina.

RIVERO, M. Y XALMA, C. (2019). Iberoamérica y la Cooperación Sur-Sur frente a las encrucijadas de la agenda internacional para el desarrollo. Documentos de trabajo (Fundación Carolina): Segunda época, 16(1).

LECHINI, G. (2009). La Cooperación Sur - Sur y la búsqueda de Autonomía en América Latina: ¿mito o realidad? Relaciones Internacionales (11), pp. 55-81. 
LECHINI, G. y MORASSO, C. (2015). La Cooperación Sur-Sur en el siglo XXI: reflexiones desde América Latina. Anuario de Integración en América Latina y El Caribe, pp. 114-133.

LORENZINI, M. y CEPPI, N. (2013). Bolivia y Venezuela como PRM's. Un análisis comparativo en torno a la cooperación internacional. En Colacrai, M. La Cooperación Internacional desde la visión de los PRM: discusiones conceptuales, diseños de políticas y prácticas sudamericanas, $1^{\circ}$ ed., pp. 189-223. UNR Editora.

MALACALZA, B. (2014). La política de cooperación al desarrollo como dimensión de la política exterior desde la Teoría de las Relaciones Internacionales. Mural Internacional, 5(2), pp. 163-176.

MALACALZA, B. (2020). Variaciones de las políticas de Cooperación Sur-Sur en América Latina: Estudio de casos. Documentos de trabajo (Fundación Carolina): Segunda época, (32), 1.

MARTínEZ, C. (2016). El Vivir Bien en el Proyecto Político del MAS en Bolivia (20062015), Tesina de grado Licenciatura en Relaciones Internacionales, Universidad Nacional de Rosario (UNR). Rosario.

MAYORGA, F. (2006). El gobierno de Evo Morales: entre el nacionalismo y el indigenismo. Nueva Sociedad(206), pp. 4-13. Recuperado de

https://nuso.org/articulo/entre-nacionalismo-e-indigenismo/

MINISTERIO DE PLANIFICACIÓN Y DESARROLLO (2007). Plan Nacional de Desarrollo Bolivia Digna, Democrática, Productiva y Soberana para Vivir Bien. Lineamientos Estratégicos 2006-2011. Ministerio de Planificación y Desarrollo de Bolivia. Recuperado de

http://www.ine.gob.bo/indicadoresddhh/archivos/Plan\%20Nacional\%20de\%20Desarrollo. pdf

MINISTERIO DE PLANIFICACIÓN Y DESARROLLO DE BOLIVIA (2013). La cooperación Internacional en Bolivia. Ministerio de Planificación y Desarrollo de Bolivia. Recuperado de http://www.aecid.bo/portal/wp-content/uploads/2014/02/CI_2013.pdf

MONTÚFAR, C. (2004). Hacia un nuevo marco interpretativo de la asistencia internacional para el desarrollo. Comentario Internacional. Revista del Centro Andino de Estudios Internacionales, (2), pp. 173-188.

MORASSO, C. (2015). La cooperación Sur-Sur argentina con África Subsahariana en materia agrícola (2003-2012), Tesis de Doctorado en Relaciones Internacionales, Universidad Nacional de Rosario (UNR). Rosario. Recuperado de https://rephip.unr.edu.ar/handle/2133/8515

OLIVERA, M. (2013). Reflexiones acerca de la relación entre el abandono de las teorías del desarrollo económico y la definición de País de Renta Media. En COLACRAI, M., La Cooperación Internacional desde la visión de los PRM: discusiones conceptuales, diseños de políticas y prácticas sudamericanas, pp. 37-60. Recuperado de http://openbiblio.flacsoandes.edu.ec/libros/digital/55014.pdf\#page $=34$

PATTACINI, V. (2013). Los Países de Renta Media: Una lectura política y debates recientes sobre su rol y su desempeño en la Cooperación Sur-Sur del espacio iberoamericano. En COLACRAI, M., La Cooperación Internacional desde la visión de los 
PRM: discusiones conceptuales, diseños de políticas y prácticas sudamericanas, pp. 15-36. Recuperado de http://openbiblio.flacsoandes.edu.ec/libros/digital/55014.pdf\#page=34

PAZ ARAUCO, V. (2014). Cambios y continuidades en la relación Estado-Cooperación Internacional (2006-2013). UNRISD Working Paper. Recuperado de https://www.econstor.eu/handle/10419/186100

PAZ RADA, E. (2018). Relaciones Internacionales y Cooperación Sur-Sur de Bolivia. En OJEDA MEDINA, T. y ECHART MUÑOZ, E. [Compiladoras], La cooperación Sur-Sur en América Latina y El Caribe. Balance de una década (2008-2018), pp. 51-62. CLACSO. Recuperado de http://biblioteca.clacso.edu.ar/clacso/gt/20190905075044/Cooperacion_SURSUR.pdf

ROMERO, R. y LANZA, M. (2012). Despatriarcalización y descolonización: retos desde las políticas públicas. En ARKONADA, K., Transiciones hacia el Vivir Bien, o la construcción de un nuevo proyecto político en el Estado Plurinacional de Bolivia, pp. 5163. La Paz: Ministerio de Culturas. Estado Plurinacional de Bolivia.

SANAHUJA, J. A. (2011). Entre los Objetivos de Desarrollo del Milenio y la cooperación sur-sur: actores y políticas de la ayuda al desarrollo en América Latina y el Caribe. Pensamiento iberoamericano, pp. 195-22. Recuperado de https://eprints.ucm.es/id/eprint/42573/

SANAHUJA, J. A. y TEZANOS VÁSQUEZ, S. (2017). Del milenio a la sostenibilidad: retos y perspectivas de la Agenda 2030 para el desarrollo sostenible. I. C. Internacionales, Ed. Revista Política y Sociedad, pp. 533-555.

SEGIB. (2020). Informe de la Cooperación Sur-Sur en Iberoamérica 2019. Madrid: Secretaría General Iberoamericana. Recuperado de https://www.informesursur.org/

SISTEMA DE NACIONES UNIDAS (2018). ODS para Vivir Bien. Alineamiento de los Objetivos de Desarrollo Sostenible con la Agenda Patriótica y el Plan Nacional de Desarrollo. Recuperado de http://www.nu.org.bo/wp-content/uploads/2018/01/ODS-paraVivir-Bien.pdf

UNDAF. (2017). Marco de complementariedad de Naciones Unidas para el Vivir Bien en Bolivia 2018-2022. ONU Bolivia. Recuperado de http://www.nu.org.bo/wpcontent/uploads/2018/07/Undaf-2018-2022.pdf

\section{Cómo citar}

MARTÍNEZ, C. (2021). Influencias internas y externas sobre la cooperación internacional en Bolivia durante el gobierno del MAS (2006-2019). Revista Integración y Cooperación Internacional, 33 (jul-dic), 35-55 